\title{
Distribution of Cardiac Geometric Patterns on Echocardiography in Essential Hypertension. Impact of Two Criteria of Stratification
}

\author{
Eduardo Cantoni Rosa, Valdir Ambrósio Moisés, Ricardo Cintra Sesso, Nárcia E. B. Kohlmann, \\ Frida Liane Plavnik, Maria Teresa Zanella, Artur Beltrame Ribeiro, Osvaldo Kohlmann Júnior \\ São Paulo, SP - Brazil
}

\begin{abstract}
Purpose - To evaluate 2 left ventricular mass index ( $L V$ MI) normality criteria for the prevalence of left ventricular geometric patterns in a hypertensive population (HT).
\end{abstract}

Methods - 544 essential hypertensive patients, were evaluated by echocardiography, and different left ventricular hypertrophy criteria were applied: 1 - classic : men $134 \mathrm{~g} / \mathrm{m}^{2}$ and women $-110 \mathrm{~g} / \mathrm{m}^{2} ; 2$ - obtained from the $95^{\text {th }}$ percentil of LVMI from a normotensive population (NT).

Results - The prevalence of 4 left ventricular geometric patterns, respectively for criteria 1 and 2, were: normal geometry $-47.7 \%$ and $39.3 \%$; concentric remodelying $-25.4 \%$ and $14.3 \%$; concentric hypertrophy $-18.4 \%$ and $27.7 \%$ and excentric hypertrophy $-8.8 \%$ and $16.7 \%$, which confered abnormal geometry to $52.6 \%$ and $60.7 \%$ of hypertensive. The comparative analysis between NT and normal geometry hypertensive group according to criteria 1, detected significative stuctural differences, " $\left.{ }^{*} p<0.05\right): L V M I-78.4 \pm 1.50 v \mathrm{~s}$ $85.9 \pm 0.95 \mathrm{~g} / \mathrm{m}^{2} *$; posterior wall thickness $-8.5 \pm 0.1 \mathrm{vs} 8.9 \pm$ $0.05 \mathrm{~mm}^{*}$; left atrium $-33.3 \pm 0.41 \mathrm{vs} 34.7 \pm 0.30 \mathrm{~mm} *$. With criteria 2, significative structural differences between the 2 groups were not observed.

Conclusion - The use of a reference population based criteria, increased the abnormal left ventricular geometry prevalence in hypertensive patients and seemed more appropriate for left ventricular hypertrophy detection and risk stratification.

Keywords- essential hypertension, left ventricular hypertrophy, criteria of hypertrophy

Hospital do Rim e Hipertensão

Mailing address: Eduardo Cantoni Rosa - Hospital do Rim e Hipertensão - Rua Borges Lagoa, 960 - 04038-002 - São Paulo, SP, Brazil

English version by Stela Maris C. Gandour
In recent years, the use of echocardiography made possible a better characterization of the cardiac morphometric and functional changes in essential hypertension ${ }^{1,2}$.

The prevalence of left ventricular hypertrophy, which is estimated in approximately $5 \%{ }^{2-4}$ according to electrocardiographic criteria, has ranged from around $20 \%$ to $40 \%$ in hypertensive populations and from 0 to $10 \%$ in normotensive populations assessed on echocardiography ${ }^{5-7}$.

The use of more sophisticated tools may also detect more accurately the early cardiac structural changes that precede left ventricular hypertrophy.

Recent studies ${ }^{8-10}$, which have assessed in a global way the spectrum of cardiac geometric changes on echocardiography in hypertensive patients, have established the concept of early cardiac remodeling. This concept along with prospective studies of morbidity and mortality ${ }^{11-16}$ have shown a greater cardiac risk for hypertensive individuals with concentric remodeling and hypertrophy, as compared with patients with normal geometry on echocardiography. This has, therefore, created a greater need for stratifying hypertensive patients in earlier phases of cardiac structural changes. Until then, these patients, unlike those patients with left ventricular hypertrophy, were considered as a low cardiovascular risk group.

The diagnosis of left ventricular hypertrophy has been based on pre-established criteria, whose limits for the cardiac mass index have been obtained in referred normotensive populations.

Therefore, adequate stratification of hypertensive patients requires pre-established limits of cardiac mass index.

Some studies, including that of Cornell University ${ }^{17}$ and the Framingham Study ${ }^{18}$, have established limit values of ventricular mass index, which were calculated based on percentiles or standard deviations of the average of the cardiac mass index in populations of normotensive males and females. These limit values were, respectively, 134 and $110 \mathrm{~g} /$ $\mathrm{m}^{2}$ at Cornell University study, and 131 and $100 \mathrm{~g} / \mathrm{m}^{2}$ in the 
Framingham Study. Later on, other studies ${ }^{7,19,20}$ established new referential values for correcting the mass by body surface area. More recent studies ${ }^{21,22}$ have proposed the use of limit values based on indexing by height, square height, and height to the power of 2.13 or 2.7 .

However, the application of these criteria in different populations should be carefully performed. Considering the diversity of the populations studied, changes in sensitivity and specificity may occur when pre-established criteria are applied for left ventricular hypertrophy, and, therefore, inadequate stratification in cardiac geometric patterns may happen.

Up to the present time, only a few studies ${ }^{7,11,23-26}$ have assessed the impact of different limit values of ventricular mass indexing on the prevalence of cardiac geometric patterns. Likewise, only a few studies ${ }^{7}$ have proposed assessing the accuracy of applying criteria usually accepted in their local populations.

The objective of the present study was to assess comparatively the prevalence of cardiac geometric patterns on echocardiography in a population of individuals with essential hypertension using one criterion widely applied (criterion 1) and a second criterion obtained from a referential normotensive population (criterion 2).

\section{Methods}

We retrospectively studied 544 patients with essential hypertension (173 males and 371 females), who underwent Doppler echocardiography in the hypertension clinic of the nephrology department at Unifesp (Federal University of São Paulo). All patients had a previous diagnosis of hypertension, which was established by assessment of medical records. Most patients $(85.4 \%)$ were under medicamentous treatment, and the remaining patients were out of medication for at least 8 weeks prior to echocardiography.

The following exclusion criteria were considered: previous diagnosis of severe hypertension; pressure levels: systolic blood pressure (SBP) $\geq 180 \mathrm{mmHg}$ or diastolic blood pressure (DBP) $\geq 110 \mathrm{mmHg}$, or both, on the day of echocardiography; secondary hypertension; a pre-established diagnosis of diabetes or fasting glycemia levels $\geq 140 \mathrm{mg} / \mathrm{dL}$, or both; chronic renal failure defined as serum creatinine $\geq 2.0 \mathrm{mg} / \mathrm{dL}$; coronary heart disease diagnosed by angiography, history of myocardial infarction, angina, or positive exercise test; and clinical signs of congestive heart failure.

Out of the local referential population, a group of 106 normotensive individuals was chosen to undergo Doppler echocardiography assessment as a control group.

On the day of the examination, demographic data and measurements of blood pressure were taken from the patients and control group. For means of analysis, only the first examination of each patient during the period studied was considered. All patients with an inadequate echocardiographic window or with valvar lesions and hemodynamic repercussion evidenced on echocardiography were excluded from the analysis.

On Doppler echocardiography, the following structural parameters were assessed: thickness of the posterior wall, of the interventricular septum, and left ventricular diameter during systole and diastole. The ventricular mass was calculated with themodified Devereux formula ${ }^{27}: 0.80\left[1.04\right.$ (DIVS+DLVPW) ${ }^{3}$ $\left.-(\mathrm{LVDD})^{3}\right]+0.6$, and the ventricular mass index obtained through correction of mass by the body surface area. Measurements of the relative thickness of the wall and relative thickness of the septum were obtained as follows: 2 DLVPW/ LVDD $^{28}$ and $2 \times$ DIVS/LVDD ${ }^{29}$, where DLVPW, DIVS, and LVDD correspond, respectively, to measurements of the thickness of the posterior wall, of the interventricular septum, and the ventricular diameter during diastole.

All measurements of the septum and the posterior wall were performed at the end of diastole, including the endocardial thickness, according to recommendations of the American Society of Echocardiography ${ }^{30}$, justifying the use of its formula modified by Devereux ${ }^{27}$. This formula approximates the values of ventricular mass obtained with the formula initially validated by the American Society of Echocardiography ${ }^{31}$, to the values of mass obtained with the equation of the convention of Penn ${ }^{32}$. This latter, despite being more accurate, applies a method of measurements less used, which excludes from the analysis the endocardial thickness of the septum and wall.

Two criteria were used for the definition of hypertrophy: 1) the classical criterion, whose limits of ventricular mass index are $134 \mathrm{~g} / \mathrm{m}^{2}$ for males and $110 \mathrm{~g} / \mathrm{m}^{2}$ for females ${ }^{17}$ (criterion 1);2) the criterion obtained from the $95^{\text {th }}$ percentile of the measurements of the ventricular mass index obtained in males and females of the referential normotensive population (criterion 2), which resulted in the respective limits of $110 \mathrm{~g} / \mathrm{m}^{2}$ and $96 \mathrm{~g} / \mathrm{m}^{2}$.

According to these criteria ( 1 and 2), the patients were classified into 4 ventricular geometry groups ${ }^{9,10,29}$, as follows: normal geometry - index of normal ventricular mass and relative thickness of the wall and relative thickness of the septum $<0.45$ (NG1 - criterion 1; NG2 - criterion 2); concentric remodeling $(\mathrm{CR})$-normal ventricular mass index and relative wall thickness or relative septum thickness $\geq 0.45$, or both, (CR1 and CR2); hypertrophy - ventricular mass index $\geq$ pre-established limits, concentric hypertrophy $(\mathrm{CH})$ if the relative wall thickness was $\geq 0.45$, and eccentric hypertrophy $(\mathrm{EH})$ if the relative wall thickness was $<0.45$.

Direct measurements of ventricular diameter and volume of the chambers obtained on echocardiography allowed direct obtainment of parameters of systolic function and hemodynamic derivatives, such as: systolic volume (SV) $=$ enddiastolic volume (EDV)-end-systolic volume (ESV), where $\mathrm{EDV}=\mathrm{LVDD}^{3}, \mathrm{ESV}=\mathrm{LVSD}^{333}$ and $\mathrm{LVSD}$ is the ventricular diameter obtained during systole; cardiac output $(\mathrm{CO})=\mathrm{SVx}$ HR (heart rate) and corrected for body surface for obtainment of the cardiac index $(\mathrm{CI})$; ejection fraction $(\mathrm{EF})=(\mathrm{EDV}$ $-\mathrm{ESV}) / \mathrm{EDV} \times 100^{34}$; percentage of fractional shortening (FS\%) obtained through the expected FS values divided by the FS values obtained, where FS $=(\mathrm{DVD}-\mathrm{SVD}) / \mathrm{DVD} x$ $100^{35}$ and expected FS $=99.9-(35.4 \log 10$ end-systolic stress); end-systolic stress (ESS) $=$ SBP x LVSD $/ 4$ x SLVPW 
$(\mathrm{LVSD}+\mathrm{SLVPW})^{36}$; contractility index (CTI), calculated by dividing ESS by LVSD $^{37}$; peripheral vascular resistance index $(\mathrm{PVRI})=$ mean blood pressure $(\mathrm{MBP}) \times \mathrm{80} / \mathrm{CO}$ where $\mathrm{MBP}=\mathrm{DBP}+(\mathrm{SBP}-\mathrm{DBP}) / 3$.

Diastolic function was assessed by mitral Doppler, using the ratios of the $\mathrm{E}$ and $\mathrm{A}$ wave $(\mathrm{cm} / \mathrm{s})$ velocities and the ratio of these waves $(\mathrm{E} / \mathrm{A})^{38}$.

For statistical analysis, demographic data were recorded with Dbase III software, and the Sigma Stat software was used. Demographic and pressure parameters, as well as echocardiographic analysis, were presented as mean \pm standard error. The student $t$ test was used for comparative analysis of demographic and pressure parameters between the normotensive and hypertensive groups. The variance test (ANOVA) was used for comparing these parameters between groups NT, NG1, and NG2, and separately for males and females. Comparative analysis of the means of the structural and hemodynamic parameters, as well as the systolic and diastolic functions, between the groups NT x HT and NT $x$ NG1 $x$ NG2 was performed through the covariance test (ANCOVA), after adjusting for age, sex, and body mass index. Comparison of prevalence of the parameters of ventricular geometry in the groups of males and females, according to both criteria, was obtained through the chisquare test.

\section{Results}

Table I shows the prevalence of cardiac geometric patterns obtained according to criteria 1 (classical criterion) and 2 (based on a normotensive population). The percentage of patients with cardiac structural changes $(\mathrm{CR}+\mathrm{CH}+$ $\mathrm{EH})$ was significantly higher when criterion 2 was used $(60.7 \%)$ as compared with criterion $1(52.6 \%)$. In addition, prevalence of cardiac hypertrophy $(\mathrm{CH}+\mathrm{EH})$ increased from $27.2 \%$ (criterion 1 ) to $45.7 \%$ when criterion 2 was used. On the other hand, a reduction in the number of patients with normal geometry on echocardiography occurred (47.4\% with criterion 1 , and $39.3 \%$ with criterion 2 ).

When assessing prevalence of different patterns of ventricular geometry for both sexes and according to criteria 1 and 2, we observed a distribution similar to that obtained with the analysis of the total population. The distribution of abnormalities according to criteria 1 and 2 in the male group was, respectively, $50.3 \%$ and $57.7 \%$, and in the female group, respectively, $53.6 \%$ and $62.0 \%$.

Table II shows pressure and demographic data of the normotensive and essentially hypertensive population. The subgroups of individuals with normal geometry obtained using the two criteria were also assessed. It is worth noting that hypertensive patients with normal geometry did not differ from the total group of hypertensive individuals in regard to age, body mass index, and blood pressure levels. These subgroups of hypertensive individuals, however, showed a significant increase in age and body mass index as compared with the normotensive individuals. In addition, a higher proportion of males was found among the hypertensive individuals.

\begin{tabular}{|c|c|c|c|c|c|c|}
\hline & & GN & $\mathrm{RC}$ & $\mathrm{HC}$ & $\mathrm{HE}$ & $\mathrm{AE}$ \\
\hline & & $(\%)$ & $(\%)$ & $(\%)$ & $(\%)$ & \\
\hline & 1 & 258 (47.4) & $138(25.4)$ & $100(18.4)$ & $48(8.8)$ & $52.6 \%$ \\
\hline Total & 2 & $214(39.3) *$ & $78(14.3)^{*}$ & $351(27.7)^{*}$ & 101 (18.6)* & $60.7 \% *$ \\
\hline \multirow[t]{3}{*}{ Males } & 1 & $86(49.7)$ & $50(28.9)$ & $28(16.2)$ & $9(5.2)$ & $50.3 \%$ \\
\hline & 2 & $73(42.2)$ & $26(15.0)^{*}$ & $49(28.3)^{*}$ & $25(14.4)^{*}$ & $57.7 \% *$ \\
\hline & 1 & $172(46.4)$ & 88 (23.7) & $72(18.4)$ & 39 (10.5) & $53.6 \%$ \\
\hline Females & 2 & $141(38.0) *$ & $52(14.0)^{*}$ & $102(27.4)^{*}$ & $76(20.5)^{*}$ & $62.0 \% *$ \\
\hline
\end{tabular}

\begin{tabular}{|lccc|}
\hline \multicolumn{2}{|c|}{ Table II - Demographic and pressure data in normotensive individuals (NT), individuals with essential hypertension (HT), and 2 subgroups of } \\
hypertensive individuals with normal cardiac geometry, according to $\mathbf{2}$ criteria of hypertrophy (HT - NG1; HT - NG2).
\end{tabular}




\begin{tabular}{|lcccc|}
\hline \multicolumn{5}{|c|}{ Table III - Demographic and pressure data in normotensive males and females (NT) and males and females with essential hypertension with normal } \\
cardiac geometry according to 2 criteria of hypertrophy (HT - NG1; HT - NG2)
\end{tabular}

Table III illustrates the demographic data obtained separately with the evaluation of males and females in the subgroups of normotensive individuals and hypertensive individuals with normal geometry, according to the 2 criteria employed.

As expected, cardiac structural parameters were significantly higher in hypertensive individuals as compared with the normotensive population as follows: ventricular mass index $-78.8 \pm 1.2$ vs $103.8 \pm 1.3 *$; left atrium $-33.4 \pm 0.41$ vs $35.2 \pm 0.2 *$; LVDD $-47.2 \pm 0.34$ vs $46.8 \pm 0.23$; LVPW $-8.5 \pm 0.10$ vs $10.2 \pm 0.08 * ;$ IVS $-8.8 \pm 0.10$ vs $10.7 \pm 0.09 *(* \mathrm{p}<0.05)$.

Table IV shows that the structural parameters were also significantly higher in the group of hypertensive individuals with normal geometry obtained with the classical criterion as compared with the group of normotensive individuals. However, when using the criterion based on the local normal population, no differences were observed in the assessment of the 2 groups.

Table IV also shows the structural evaluation in subgroups of males and females. It is worth noting that in the male subgroup, no structural differences were observed in the NG2 group as compared with the group of normotensive individuals (as in the global evaluation). In the female subgroup, significant differences were observed between the 2 groups, despite the fact that by applying criterion 2 the structural parameters of the NG2 group were more close to those of the normotensive group.

Cardiac functional alterations resulting from hypertension were not influenced by the use of one or the other criterion. Patients with normal geometry obtained according to both criteria showed an increase in the peripheral vascular resistance, end-systolic stress, cardiac index, fractional shortening, and contractility index, when compared with the normotensive individuals (Table V). In regard to the diastolic function, similar reductions in the $\mathrm{E}$ wave/A wave ratio were observed in both groups as compared with the normotensive individuals. This was also observed when males and females were separately evaluated.

\begin{tabular}{|c|c|c|c|c|c|}
\hline & & NT & $\mathrm{HT} \mathrm{NG}_{1}$ & $\mathrm{HT} \mathrm{NG}{ }_{2}$ & $\mathrm{P}$ \\
\hline & Total & $78.4 \pm 1.5$ & $85.9 \pm 0.95^{*}$ & $81.6 \pm 0.85$ & $<0.0001$ \\
\hline LVMI & Males & $83.9 \pm 2.3$ & $91.9 \pm 1.8^{*}$ & $87.2 \pm 1.5$ & 0.01 \\
\hline \multirow[t]{2}{*}{$\left(\mathrm{g} / \mathrm{m}^{2}\right)$} & Females & $73.3 \pm 1.8$ & $82.9 \pm 1.05^{*}$ & $78.7 \pm 0.96^{*+}$ & $<0.0001$ \\
\hline & Total & $33.3 \pm 0.41$ & $34.7 \pm 0.30^{*}$ & $34.2 \pm 0.34$ & 0.02 \\
\hline LA & Males & $34.1 \pm 0.55$ & $36.4 \pm 0.59^{*}$ & $35.2 \pm 0.74$ & 0.02 \\
\hline \multirow[t]{2}{*}{$(\mathrm{mm})$} & Females & $32.5 \pm 0.58$ & $33.8 \pm 0.31$ & $33.7 \pm 0.34$ & NS \\
\hline & Total & $47.3 \pm 0.35$ & $47.6 \pm 0.25$ & $47.0 \pm 0.24$ & NS \\
\hline LVDD & Males & $49.1 \pm 0.48$ & $50.0 \pm 0.46$ & $49.2 \pm 0.43$ & NS \\
\hline \multirow[t]{2}{*}{$(\mathrm{mm})$} & Females & $45.7 \pm 0.42$ & $46.4 \pm 0.25$ & $45.8 \pm 0.24$ & NS \\
\hline & Total & $8.5 \pm 0.12$ & $8.9 \pm 0.05^{*}$ & $8.7 \pm 0.05$ & $<0.001$ \\
\hline LVPW & Males & $9.0 \pm 0.16$ & $9.3 \pm 0.09 *$ & $9.10 \pm 0.09$ & 0.02 \\
\hline \multirow[t]{2}{*}{$(\mathrm{mm})$} & Females & $8.0 \pm 0.16$ & $8.7 \pm 0.06^{*}$ & $8.5 \pm 0.06^{*}$ & $<0.0001$ \\
\hline & Total & $8.8 \pm 0.13$ & $9.0 \pm 0.07$ & $8.8 \pm 0.07$ & NS \\
\hline IVS & Males & $9.3 \pm 0.19$ & $9.4 \pm 0.09$ & $9,2 \pm 0,09$ & NS \\
\hline$(\mathrm{mm})$ & Females & $8.4 \pm 0.16$ & $8.8 \pm 0.09^{*}$ & $8,6 \pm 0,09$ & 0.003 \\
\hline
\end{tabular}




\begin{tabular}{|l|cc|}
\hline \multicolumn{4}{|c|}{ Table V - Hemodynamic parameters (systolic and diastolic function) in normotensive individuals (NT), individuals with essential hypertension (HT), } \\
and hypertensive individuals with normal cardiac geometry (HT - NG1; HT - NG2).
\end{tabular}

\section{Discussion}

The diagnosis of ventricular hypertrophy in hypertension requires pre-established criteria derived from normotensive populations, and these criteria are based on the normal limits of the cardiac mass index ${ }^{17,18}$.

One of the currently most used criteria is that derived from studies at Cornell University ${ }^{17}$, which is based on a normotensive population of New York City (ventricular mass index of $134 \mathrm{~g} / \mathrm{m}^{2}$ for males and $110 \mathrm{~g} / \mathrm{m}^{2}$ for females).

When the limits of thickness of the septum and the left ventricularposterior wall are taken into consideration, stratification in 4 cardiac geometric patterns is possible. This has proven to be useful as it allows the identification of a significant percentage of hypertensive individuals in the population, who, despite their ventricular mass index within the normal range, show an increase in the relative thickness of the septum or the posterior wall, or both, as compared with individuals with normal geometry 10,12,29. These patients, classified as having concentric remodeling, are currently known to have higher cardiovascular morbidity and mortality ${ }^{11,12}$.

In our study, the different prevalences of ventricular geometric patterns obtained with the use of both criteria (Table I) allow the identification of a substantial number of individuals with hypertrophy $(\mathrm{CH}$ and $\mathrm{EH})$ or with some kind of cardiac structural change $(\mathrm{CH}, \mathrm{EH}$, and $\mathrm{CR})$ in a population of mild to moderate hypertensive individuals both for the male and female groups.

Using criterion 1, $47.4 \%$ of the patients had NG, $25.4 \%$ $\mathrm{CR}$, and $27.2 \%$ hypertrophy, adding to a total of $52.6 \%$ of patients with cardiac structural changes. Similar prevalence was found in the evaluation of males and females separately.

Using the criterion based on the normotensive population (criterion 2), we found $45.7 \%$ of individuals with hypertrophy in the total group, $42.7 \%$ in the male group, and $47.9 \%$ in the female group, constituting along with the percentile of individuals with concentric remodeling a total of, respectively, $60.7 \%, 57.8 \%$, and $62.0 \%$ of hypertensive individuals with some kind of structural alteration. This means a significantincrement of $8.1 \%, 7.5 \%$, and $8.4 \%$ of patients with an increased risk in stratification.
On the other hand, patients with ventricular mass index, and septal and wall thickness within normal range have normal geometry and, theoretically, should not differ from normotensive patients in regard to cardiac structural parameters. However, the results of our study have shown that individuals classified as having normal geometry by applying criterion 1 had significantly higher structural changes in mass ventricular index and relative thickness of the septum and wall than the referential population of normotensive individuals.

When we applied the criterion based on the $95^{\text {th }}$ percentile of the mean of the ventricular mass indices obtained from a local referential population instead of the criterion of Cornell University, significant differences were no longer observed in the structural parameters of individuals with normal geometry and those of the normotensive population. When analyzing males and females separately, however, the results obtained showed that in the female group, despite the approximation of the structural parameters between the NG group and the normotensive group, when using criterion 2, significant differences in the assessment of the ventricular mass index and LVPW occurred. In addition, no significant differences were observed in most morphometric evaluations of NG1 and NG2 subgroups.

Nevertheless, the application of criterion 2 seemed more appropriate for detecting cardiac hypertrophy in this population, because a greater approximation of the structural parameters of the NG and normotensive groups occurred.

The fact that pre-established criteria obtained from specific populations might not be applied with the same accuracy for other populations had already been observed and motivated the studies at Cornell University. This showed that the application of the criteria obtained in the Framingham Study ${ }^{18}$ to a population of New York City ended up by overestimating the prevalence of hypertrophy in groups of normotensive individuals and groups of individuals with borderline and sustained hypertension in this population ${ }^{7}$. On that occasion, $9.4 \%$ of the normotensive individuals, who supposedly had normal cardiac geometry, were classified as having left ventricular hypertrophy, and a prevalence of $19.6 \%$ of hypertrophy in borderline hyperten- 
sive individuals was detected; on the other hand, with the use of local criteria, this prevalence was $12.4 \%$. The low specificity (negative predictive value) of the criteria of the Framingham Study for the population of New York City $(90.6 \%)$ was attributed to population changes in lifestyle, prevalence of obesity, sedentary lifestyle, etc.

Differences in body constitution and life habits between our population and that of New York City may perhaps explain the better accuracy obtained when a criterion based on the local population was used. This was stressed when we applied criterion 1 in our normotensive population, which provided a prevalence of $0.9 \%$ of individuals with hypertrophy in a population that supposedly had no hypertrophy. Therefore, we obtained a $99.1 \%$ specificity for criterion 1 , which is extremely high when one considers the ideal $97 \%$ specificity ${ }^{7}$, with no loss in sensitivity (positive predictive value).

A recent study ${ }^{26}$ assessed the use of different criteria of hypertrophy in a normotensive population and in a previously selected subpopulation based on the presence of hypertrophy on the electrocardiography (subpopulation of the LIFE Study). This study could well analyze the inverse relation existing between specificity and sensitivity for the criteria applied and also the impact on the prevalence of hypertrophy, which ranged from $42 \%$ to $72 \%$ in this study, depending on the criterion used.

Other studies have shown that the application of different criteria ends up in modifying the prevalence of ventricular geometric patterns depending on the population subgroups analyzed (according to sex, age, body mass index), on the criterion of ventricular mass correction used (body surface, height, square height), or on the covariables present in the population being studied (level of hypertension, medication use, blood pressure control, etc).
In the VITAE Study ${ }^{25}$, the echocardiographic assessment of a large population of essential hypertension obtained from reference centers in Spain provided a prevalence of ventricular hypertrophy and of concentric remodeling that ranged from $59.2 \%$ to $72.2 \%$ and from $6.5 \%$ to $11.4 \%$, respectively, depending on the criterion used.

The use of the same criteria applied in our study $(110 \mathrm{~g} /$ $\mathrm{m}^{2}$ and $134 \mathrm{~g} / \mathrm{m}^{2}$ ) in 510 participants of the HOT Study ${ }^{39}$ provided a prevalence of hypertrophy of $62 \%$. In another study ${ }^{40}$, a prevalence of hypertrophy of $25 \%$ for males and $26 \%$ for females was found with the criterion of $134 \mathrm{~g} / \mathrm{m}^{2}$ and $102 \mathrm{~g} /$ $\mathrm{m}^{2}$, which is very similar to that used in our study.

Considering the prognostic implications associated with the diagnosis of ventricular hypertrophy and remodeling changes in hypertensive individuals ${ }^{41}$, the standardization of criteria has been emphasized, confirming the need for establishing specific population criteria.

As expected, the use of a more adequate criterion of normality for the ventricular mass index did not alter accuracy in detecting early functional changes that accompany the development of left ventricular hypertrophy ${ }^{10,29,42,43}$. In fact, functional (systolic and diastolic) and hemodynamic changes in hypertensive patients with normal cardiac geometry were equally demonstrated when both criteria were used.

In conclusion, the findings of the present study suggest that the use of a criterion of normality based on a referential normotensive population may perhaps be more appropriate for detecting ventricular hypertrophy and stratification of the hypertensive population in different cardiac geometric patterns. Obtaining these criteria based on the assessment of a larger referential normotensive population in our country is required.

\section{References}

1. Dunn FG, Chandraratna P, de Carvalho JG, et al. Pathophysiologic assesment of hypertensive heart disease with echocardiography. Am J Cardiol 1977; 39: 789-95.

2. Savage DD, Drayer JM, Henry WL. Echocardiographic assesment of cardiac anatomy and function in hypertensive subjects. Circulation 1979; 59: 623-32.

3. Hypertension Detection and Follow-Up Program Cooperative Group. Five year findings of the Hypertension Detection and Follow-Up Program: Reduction of mortality of persons with high blood pressure, including mild hypertension. JAMA. 1979; 242: 2562-71.

4. Kannel WB, Gordon T, Opputt D. Left ventricular hypertrophy by electrocardiogram: prevalence, incidence and mortality in the Framingham Study. Ann Int Med 1969; 71: 89-105.

5. Devereux RB, Pickering TG, Harschfield GA. Left ventricular hypertrophy in patients with hypertension: importance of blood pressure responses to regularly recurring stress. Circulation 1983; 68: 470-6.

6. Devereux RB, Casale PN, Hammond IW. Echocardiographic detection of pressure - overload left ventricular hypertrophy: Effect of criteria and patient population. J Clin Hypertens 1987; 3: 66-78.

7. Hammond IW, Alderman MH, Alderman MH. The prevalence and correlates of echocardiographic left ventricular hypertrophy among employed patients with uncomplicated hypertension. J Am Coll Cardiol 1986; 7: 639-50.

8. Savage DD, Garrison RJ, Kannel WB. The spectrum of left ventricular hypertrophy in a general population sample: the Framingham Study. Circulation 1987; 75(suppl I): 26-33.
9. Campus S, Malavasi A, Ganau A. Systolic function of the hypertrophied left ventricle. J Clin Hypertens 1987; 3: 79-87.

10. Ganau A, Devereux RB, Roman MJ, et al. Patterns of left ventricular hypertrophy and geometric remodeling in essential hypertension. J Am Coll Cardiol 1992; 19: $1550-8$.

11. Casale PN, Devereux RB, Milner M. Value of echocardiographic measurement of left ventricular mass in predicting cardiovascular morbid events in hypertensive men. Ann Intern Med 1986; 105: 173-8.

12. Koren MJ, Devereux RB, Casale PN, et al. Relation of left ventricular mass and geometry to morbidity and mortality in uncomplicated essential hypertension. Ann Intern Med 1991; 114: 345-52.

13. Verdecchia P, Schillaci G, Borgioni C, et al. Adverse prognostic significance of concentric remodeling of the left ventricle in hypertensive patients with normal left ventricular mass. J Am Coll Cardiol 1994; 73: 247-52.

14. Krumholz HM, Larson M, Levy D. Prognostic of left ventricular geometric patterns in the Framingham Heart Study. J Am Coll Cardiol 1995; 25: 879-84.

15. Verdecchia P, Schillaci G, Borgioni C, et al. Prognostic value of left ventricular mass and geometry in systemic hypertension. Am J Cardiol 1996; 78: 197-202.

16. Ghali JK, Liao Y, Cooper RS. Influence of left ventricular geometric patterns in prognosis in patients with or without coronary artery disease. J Am Coll Cardiol 1998; 31: 1635-40.

17. Devereux RB, Lutas EM, Casale PN. Standardization of M-mode echocardiographic left ventricular anatomic measurements. J Am Coll Cardiol 1984; 4: 1222-30. 
18. Levy D, Savage DD, Garrison RJ, et al. Echocardiographic criteria for left ventricular hypertrophy: the Framingham Heart Study. Am J Cardiol 1987; 59: 556-960.

19. Ghali JK, Liao Y, Simmon B, et al. The prognostic role of left ventricular hypertrophy in patients with or without coronary artery disease. Ann Intern Med 1992; 117: 831-6.

20. Devereux RB, Dahlof B, Levy D, et al. Comparison of enalapril versus nifedipine to decrease left ventricular hypertrophy in systemic hypertension (the Preserv Trial). Am J Cardiol 1996; 78: 61-5.

21. Lauer MS, Okir PM, Anderson KM, et al. Impactof echocardiographic left ventricular mass in mechanistic implications of exercise testing parameters. Am J Cardiol 1995; 76: 952-6.

22. De Simone G, Devereux RB, Roman MJ, et al. Relation of obesity and gender to left ventricular hypertrophy in normotensive and hypertensive adults. Hypertension 1994; 23: 600-8.

23. Vasan RS, Larson MG, Levy D, et al. Distribution and categorization of echocardiographic measurements in relation to reference limits. The Framingham Heart Study: formulation of height and sex specific classification and its prospective validation. Circulation 1997; 96: 1863-73.

24. Roman MJ, Pickering TG, Schwartz JE, et al. Relation of arterial structure and function to left ventricular geometric patterns in hypertensive adults. J Am Coll Cardiol 1996; 28: 751-6.

25. Coca A, Gabriel R, de la Figuera M, et al. The impact of different echocardiographic diagnostic criteria on the prevalence of left ventricular hypertrophy in essential hypertension: the VITAE Study. J Hypertens 1999; 17: 1471-80.

26. Wachtell K, Bella JN, Liebson PR, et al. Impact of different partition values on prevalences of left ventricular hypertrophy and concentric geometry in a large hypertensive population. The LIFE Study. Hypertension 2000; 35: 6-12.

27. Devereux RB, Alonso DR, Lutas GM. Echocardiographic assessment of left ventricular hypertrophy: comparison to necropsy findings. Am J Cardiol 1986; 57: 480-458.

28. Reichek N, Devereux RB. Reliable estimation of peak left ventricular systolic pressure by M-mode echographic determined end - diastolic relative wall thickness: identification of severe valvular aortic stenosis in adult patients. Am Heart J 1982; 103: 202-9.

29. Verdecchia P, Porcellati C, Zampi I, et al. Asymmetric left ventricular remodeling due to isolated septal thickening in patients with systemic hypertension and normal left ventricular mass Am J Cardiol 1994; 73: 247-52.
30. Sahn DJ, de Maria A, Kisslo J, et al. The committee on M- mode standardization of the American Society of Echocardiography. Recommendations regarding quantitation on M- mode echocardiography results of a survey of echocardiographic measurements. Circulation 1978; 58: 1072-83.

31. Troy BL, Pombo J, Rockley CE. Measurement of left ventricular wall thickness and mass by echocardiography. Circulation 1972; 45: 602-11.

32. Devereux RB, Reichek N. Echocardiographic determination of left ventricular mass in men with anatomic validation of the method. Circulation 1977; 55: 613-8.

33. Wallerson DC, Ganau A, Roman RJ, Devereux RB. Measurement of cardiac output bym - mode and two dimensional echocardiography: application to patients with hypertension. Eur Heart J 1990; 11(suppl I): I 67-I 78.

34. Quinones MA, Pickering E, Alexander JK. Percentage of shortening of the echocardiographic left ventricular dimension: its use in determining ejection fraction and stroke volume. Chest 1978; 74: 59-65.

35. Lutas EM, Devereux RB, Laragh JH, et al. Increased cardiac performance in mild essential hypertension. Hypertension 1985; 7: 979-88.

36. Reichek NI, Wilson J, St. John Sutton M, et al. Noninvasive determination of left ventricular end - systolic stress: validation of the method and initial application. Circulation 1982; 65: 99-108.

37. Sagawa K, Suga H, Shoukas A, et al. End - systolic pressure / volume ratio: a new index of ventricular contractility. Am J Cardiol 1977; 40: 748-53.

38. Pearson AC, Labovitz AJ, Mrosek D, et al. Assessment of diastolic function in hypertrophied hearts: comparison of doppler echocardiography and M- mode echocardiography. Am Heart J. 1987; 113: 1417-25.

39. Zabalgoitia M. Left ventricular mass and function in primary hypertension. Am J Hypertens 1996; 9: 55-9.

40. Tingleff J, Munch M, Jakobsen TJ, et al. Prevalence of left ventricular hypertrophy in a hypertensive population. Eur Heart J 1996; 17: 143-9.

41. Liao Y, Cooper RS, Durazo-Arvizu R, et al. Prediction of mortality risk by different methods of indexation of left ventricular mass. J Am Coll Cardiol 1997; 29: 641-7.

42. Inouye IK, Massie BM, Loge D, et al: Abnormal left ventricular filling: an early finding in mild to moderate systemic hypertension. Am J Cardiol1985; 53: 1032-6.

43. Ren F, Pancholy SB, Iskandrian AS, et al. Doppler echocardiographic evaluation of the spectrum of left ventricular diastolic disfunction in essential hypertension. Am Heart J 1994; 127: 907-12. 